\title{
PENGUATAN PEMAHAMAN TERHADAP APLIKASI ALABAR DALAM TEKNOLOGI MODERN BAGI SISWA SMA NEGERI 1 PRAYA
}

\section{STRENGTHENING UNDERSTANDING OF ALJABAR APPLICATIONS IN MODERN TECHNOLOGY FOR STUDENTS OF SENIOR HIGH SCHOOL 1 PRAYA}

\author{
I Gede Adhitya Wisnu Whardana, Mamika Ujianita Romdhini, Ni Wayan Switrayni, Irwansyah \\ Program Studi Matematika, Fakultas Matematika dan Ilmu Pengetahuan Alam, Universitas \\ Mataram
}

Jalan Majapahit Nomor 62, Kota Mataram, Provinsi NTB, 83115

Alamat korespondensi: irw@unram.ac.id

(Tanggal Submission: 30 Desember 2019, Tanggal Accepted: 22 April 2020 )

\begin{abstract}
ABSTRAK
Kriptografi dan teori kode merupakan dua cabang matematika yang terkait langsung dengan teknologi informasi modern. Dua cabang ini merupakan aplikasi dari konsep-konsep dasar dalam ilmu aljabar. Namun, saat ini jumlah peminat aljabar ataupun matematika secara umum sangatlah kurang. Padahal, ilmu ini sangat diperlukan untuk pengembangan teknologi komunikasi informasi yang lebih aman dan reliabel. Oleh karena itu, kegiatan ini bertujuan untuk meningkatkan motivasi, minat, dan kesadaran siswa sekolah menengah terhadap pentingnya aljabar dan matematika secara umum. Metode pendekatan yang akan diterapkan adalah melalui workshop yang berisi pemaparan tentang teknologi komunikasi modern dan konsep aljabar yang ada di belakangnya. Kegiatan workshop dilaksanakan di SMAN 1 Praya. Setelah kegiatan ini, para siswa SMAN 1 Praya memiliki tambahan pengetahuan terkait aplikasi aljabar di dalam dunia teknologi modern. Selain itu, para siswa juga memiliki tambahan motivasi untuk mempelajari matematika, khususnya aljabar.
\end{abstract}

Kata kunci: kriptografi, teori kode, aljabar, teknologi modern

\section{PENDAHULUAN}

Teknologi modern, terutama dalam bidang pertukaran informasi, telah memberikan kemudahan pada hampir semua aspek kehidupan manusia, seperti komunikasi, transaksi keuangan, pencarian informasi, dan lain-lain. Contoh spesifik di antaranya aplikasi chatting, voice call, video call, transaksi ATM, mobile banking, internet banking, dan komunikasi satelit. Dua di antara faktor utama yang menentukan apakah suatu teknologi modern, misalnya dalam komunikasi dan transaksi, dapat dimanfaatkan atau tidak adalah faktor keamanan dan faktor reliabilitas. Faktor keamanan di sini secara spesifik bertujuan agar komunikasi atau transfer informasi antar dua pihak tidak dapat diretas atau diganggu oleh pihak ketiga yang tidak bertanggung jawab. Sedangkan, faktor reliabilitas sendiri dimaksudkan agar informasi yang disimpan atau disampaikan melalui channel atau jaringan tetap utuh seperti aslinya, tidak kurang dan tidak lebih.

Keamanan informasi dalam teknologi masa kini bertumpu pada suatu cabang matematika yang disebut dengan kriptografi atau ilmu persandian. Sedangkan, reliabilitas channel atau jaringan sendiri bertumpu pada cabang matematika lain yang disebut dengan teori kode. Lebih jauh, secara umum, dasar-dasar dibangunnya kriptografi dan teori kode sendiri adalah aljabar abstrak dan aljabar vektor. Sehingga, bisa dikatakan bahwa, secara tidak langsung, aljabar merupakan fondasi dari teknologi modern, terutama teknologi yang menyangkut pertukaran/arus informasi. 
Secara umum, aljabar ataupun matematika secara umum bukanlah bidang yang memiliki banyak peminat. Ada banyak sumber data sampel yang dapat membenarkan kondisi ini. Dua diantaranya adalah data peminat aljabar di Program Studi Matematika, FMIPA, Universitas Mataram, dan data peminat jurusan Matematika pada ujian masuk perguruan tinggi. Sehingga, dapat dinyatakan bahwa di SMAN 1 Praya juga mengalami masalah di atas. Pada dua sumber data tersebut bisa dilihat bahwa aljabar ataupun matematika secara umum bukanlah ilmu yang paling diminati. Padahal, penguasaan aljabar sangat diperlukan dalam pengembangan sistem komunikasi yang lebih aman dan lebih reliabel.

Oleh karena itu, perlu dilakukan suatu usaha agar para siswa, khususnya siswa sekolah menengah, memiliki minat belajar matematika yang tinggi. Salah satu cara yang dilakukan adalah melalui workshop aplikasi aljabar dalam teknologi modern. Sehingga, diharapkan, dengan adanya pengetahuan terkait pentingnya pengetahuan ini, minat dan motivasi para siswa dalam mempelajari matematika dapat meningkat.

\section{METODE KEGIATAN}

\section{Persiapan Kegiatan}

Pada tahap ini, dilakukan penyiapan materi workshop yang berisi tentang aplikasi aljabar dalam teknologi modern yang sesuai untuk siswa SMAN 1 Praya. Materi yang dipersiapkan dalam bentuk presentasi dan permainan tebak angka. Materi presentasi terdiri dari presentasi tentang teori kode dan aplikasinya, serta presentasi tentang ilmu persandian (kriptografi) dan aplikasinya. Permainan tebak angka bertujuan untuk mensimulasikan cara kerja kode dalam pengiriman dan penerimaan pesan lewat satelit.

\section{Pelaksanaan Kegiatan}

Pada tahap ini, dilaksanakan workshop yang terdiri dari dua topik umum, yaitu teori kode dan aplikasinya, serta ilmu persandian (kriptografi) dan aplikasinya. Workshop dilaksanakan dengan presentasi dan diskusi. Presentasi dilakukan oleh dosen aljabar. Kemudian, pada jeda diskusi, diadakan permainan tebak angka yang dipandu oleh dua mahasiswa Prodi Matematika.

\section{Pelaporan Kegiatan}

Tahap terakhir ini dilakukan dengan penyusunan laporan akhir kegiatan pengabdian. Laporan kegiatan mendiskripsikan pelaksanaan kegiatan serta output yang dicapai. Laporan kegiatan juga dilengkapi dengan dokumentasi kegiatan. Selain itu, pelaksanaan kegiatan pengabdian ini dituliskan juga ke dalam bentuk artikel pengabdian.

\section{HASIL DAN PEMBAHASAN}

Untuk memecahkan permasalahan yang ada di mitra seperti telah disampaikan sebelumnya, telah dilakukan workshop gambaran umum aplikasi aljabar dalam teknologi modern. Kegiatan workshop tersebut dilaksanakan pada tanggal 1 Agustus 2019 dan bertempat di SMA Negeri 1 Praya.

Kegiatan ini diawali dengan pembukaan acara oleh anggota tim pengabdian yang berisi sambutan dan ucapan terimakasih atas partisipasi peserta. Kegiatan berikutnya adalah kegiatan presentasi aplikasi aljabar dalam teknologi modern selama 60 menit. Pada tahapan ini, isi presentasi adalah topik-topik terkait dengan kriptografi dan teori kode. Kegiatan ini diselingi dengan permainan tebak angka untuk mengilustrasikan cara kerja kode pada saluran komunikasi saat transmisi data.

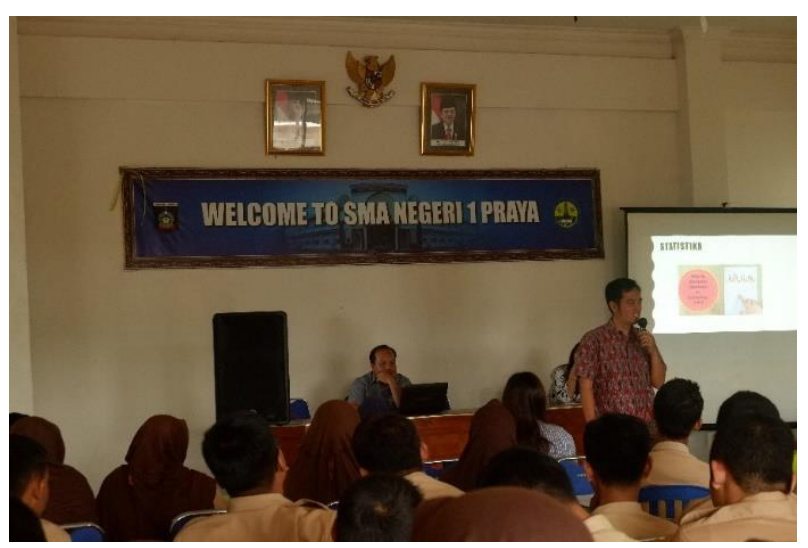




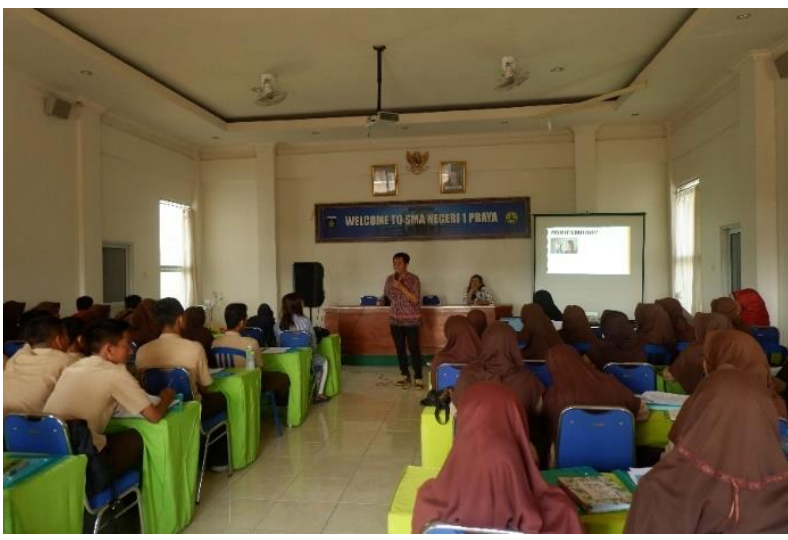

Gambar 1. Penyampaian materi dan diskusi
Secara umum, materi yang didiskusikan digambarkan pada Gambar 2. Dalam sistem telekomunikasi, pesan yang akan dikirimkan dapat berupa teks, gambar, video, atau suara, lihat (Huffman dan Pless, 2010). Sebelum dikirim, pesan ini terlebih dahulu dikonversi menjadi objek lain. Objek lain ini berupa serangkaian simbol 0 dan 1. Salah satu tujuan konversi ini adalah agar pesan aslinya tetap dapat dibaca kembali secara utuh meskipun mengalami gangguan. Gangguan yang dimaksud sendiri dapat berupa cuaca, goresan, dan lain-lain.

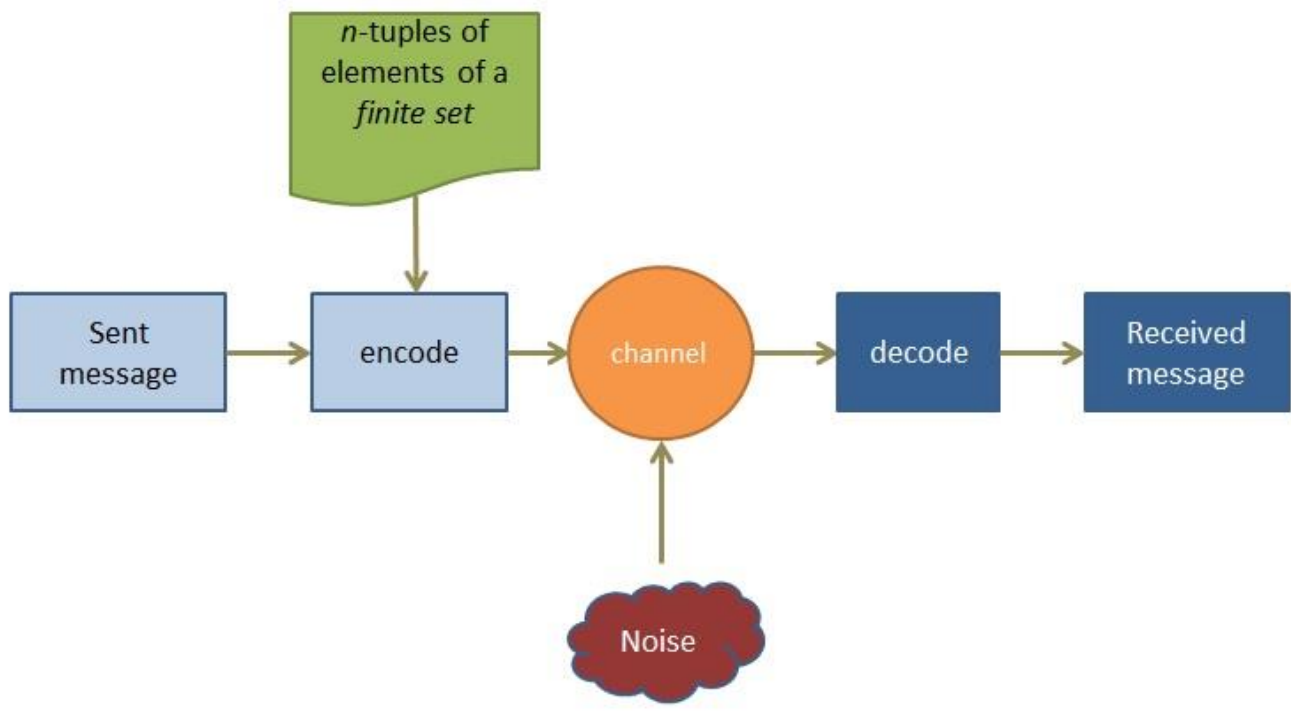

Gambar 2. Gambaran skema penggunaan kode pada saluran komunikasi

Aplikasi dari skema seperti ini dapat ditemukan dalam komunikasi satelit, pengiriman pesan teks, foto, video, memori komputer, compact disk, dan pita magnetik ATM. Pada komunikasi satelit, gangguan yang mungkin terjadi dapat berupa gangguan cuaca, mati lampu, dan lain-lain. Sedangkan pada memori atau compact disk, gangguan dapat berupa goresan atau terjadinya patah fisik. Hal ini dapat menyebabkan pesan yang terkirim atau tersimpan tidak dapat dibaca kembali. Sehingga, skema pengkodean adalah sangat penting.

Selain diterapkan untuk recovery pesan dalam komunikasi, skema di atas juga dapat digunakan dalam keamanan pesan, lihat (Singh, 2003). Dalam kaitannya dengan keamanan data, skema di atas biasanya disebut dengan skema persandian. Persandian dilakukan dengan mengkonversi pesan asli menjadi kode tertentu. Kode ini diusahakan tidak dapat dibaca oleh pihak ketiga. Aplikasi dari skema ini dapat kita lihat pada keamanan data digital, keamanan transaksi perbankan seperti di ATM, mobile banking, dan internet banking.

Proses pengkodean dan pengembalian pesan dari kode memerlukan pengetahuan aljabar. Oleh karena itu, pengetahuan dan penguasaan bidang aljabar sangatlah penting di saat ini. Beberapa penelitian terkait kode dan persandian dengan cara pandang aljabar dapat dilihat di (Irwansyah dan kawan-kawan, 2018), (MuchtadiAlamsyah dan Irwansyah, 2019), dan (Irwansyah dan kawan-kawan, 2016).

Kegiatan berikutnya adalah penutup, acara ditutup oleh ketua Kelompok Riset Aljabar Program Studi Matematika, FMIPA, Universitas Mataram. 
Melalui kegiatan workshop isu-isu strategis dalam aljabar ini diperoleh:

1. Para siswa SMAN 1 Praya termotivasi untuk mempelajari aljabar lebih jauh. Hal ini terlihat dari proses diskusi pada sesi presentasi dan keterlibatan peserta dalam games.

2. Pengetahuan para siswa SMAN 1 Praya terkait aplikasi aljabar dalam teknologi modern meningkat. Hal ini disebabkan karena dalam sesi presentasi, disajikan dasar-dasar teori kode dan kriptografi serta aplikasinya di dunia nyata.

Dalam pelaksanaan kegiatan Pengabdian Kepada Masyarakat ini, terdapat beberapa faktor yang mendukung kesuksesan kegiatan ini, antara lain sebagai berikut :

1. Dukungan dari Kepala Sekolah SMA Negeri 1 Praya beserta jajarannya yang telah menyediakan fasilitas ruangan dan siswanya demi terlaksananya kegiatan ini.

2. Dukungan para siswa SMA Negeri 1 Praya yang sangat antusias dan bersemangat dalam mengikuti kegiatan workshop ini.

3. Dukungan dari beberapa mahasiswa yang terlibat dalam kegiatan ini sehingga kegiatan ini sukses dilaksanakan.

\section{KESIMPULAN DAN SARAN}

Dari pelaksanaan kegiatan pengabdian kepada masyarakat ini, dapat disimpulkan bahwa kegiatan tersebut sangat bermanfaat bagi para siswa SMAN 1 Praya, yaitu dalam hal :
1. Meningkatnya motivasi para siswa untuk mempelajari aljabar lebih dalam.

2. Meningkatnya pengetahuan para siswa di bidang aljabar dan aplikasinya dalam teknologi modern.

Adapun saran yang dapat diberikan adalah hendaknya kegiatan ini dapat dilakukan secara lebih rutin sehingga dapat memaksimalkan hasil yang dicapai.

\section{DAFTAR PUSTAKA}

Huffman, W.C., Pless, V., 2010. Fundamentals of Error-Correcting Codes. Cambridge University Press.

Singh, S., 2003. The Code Book: The Secrets Behind Codebreaking. Ember: New York.

Irwansyah, Barra, A., Muchtadi-Alamsyah, I., Muchlis, A., Suprijanto, D.. 2018. Skew-cyclic codes over $B_{k}$. Journal of Applied Mathematics and Computing

Muchtadi-Alamsyah, I., Irwansyah, 2019. Asymmetric quantum codes from skew cyclic codes over $B_{1}$. AIP Conference Proceedings Vol. 2192 Issue 1040008.

Irwansyah, Barra, A., Dougherty, S.T., Muchlis, A., Muchtadi-Alamsyah, I., Sole, P., Suprijanto, D., Yemen, O. 2016. $\Theta_{S}$-cyclic codes over $A_{k}$. International Journal of Computer Mathematics: Computer Systems Theory Vol. 1 Issue 1 p. 14-31. 